\title{
Lasers: light in the dental office
}

\begin{abstract}
Lasers have been largely used in the field of dentistry, they provide a high quality, precision treatment modality with and a great reduction or lack of posttreatment pain, making the patient experience somewhat easier. Lasers play an integral part in treating oral mucosal lesions. Its use is not only limited to oral mucosal lesions alone but also stepping into the field of endodontics and periodontics. Lasers have already established itself in the field of surgery.
\end{abstract}

Volume 7 Issue 4 - 2020

\author{
Rashmi M,' Jayrekha Tadiparthi, ${ }^{2}$ Latha \\ Muniswamy, ${ }^{3}$ Megha Chethan, ${ }^{4}$ Karthik D \\ Yadav $^{5}$ \\ 'Master of Dental surgery, Department of Public health \\ Dentistry, KGF College of Dental Sciences, India \\ ${ }^{2}$ Master of Dental surgery, Department of oral medicine and \\ radiology, India \\ ${ }^{3}$ Master of Dental surgery, Department of Oral pathology, KGF \\ College of Dental Sciences, India \\ ${ }^{4}$ Master of Dental surgery, Professor and HOD, Department \\ of Conservative Dentistry and Endodontics, KGF College of \\ Dental Sciences, India \\ ${ }^{5}$ Master of Dental surgery, Senior Lecturer, Department of oral \\ medicine and radiology, KGF College of Dental Sciences, India
}

Correspondence: Karthik D Yadav, Master of Dental surgery, Senior Lecturer, Department of oral medicine and radiology, KGF College of Dental Sciences, India,

Email karthikyadvd@gmail.com

Received: June 23, 2020 | Published: July 27, 2020

\section{Introduction}

Lasers have been largely used over the world with varied applications in innumerable fields. Their efficiency is time tested and has been proven to be a valuable tool over the period of time. In the field of dentistry, they provide a high quality, precision treatment modality with and a great reduction or lack of posttreatment pain, making the patient experience somewhat easier. Dental procedures performed today with the laser are so effective that it avoids the patient going through the avoidance of pre and post-operative pain and discomfort, which encourages the patient to get over any fear that results from the dental procedures. This encourages positive reinforcement in the patient.

\section{Laser application in day to day practice in the oral mucosa}

\section{Frictional keratosis}

It is a white non scrapable lesion results from chronic low-grade contact, either from cheek biting, ill-fitting denture or sharp cusps of the teeth. The lesion can be treated with soft laser therapy with the possibility of excision of small lesions using carbon dioxide laser., ${ }^{1,2}$

\section{Smokeless tobacco induced white lesions}

These are white non scrapable lesions induced by the chronic usage of smokeless tobacco, which are treated by carbon dioxide lasers depending on their size and location. ${ }^{1,2}$

\section{Nicotinic stomatitis}

They appear as a red dots surrounded by a halo of white keratin. It is caused by pipe smoking or cigar smoking and usually asymptomatic, unless secondarily infected. If the patient complains of pain, then the lesions are vaporized after multiple punch biopsies. Carbon dioxide in continuous mode is used to treat the lesion. ${ }^{2}$

\section{Mucocele}

A watery dome shaped transparent fluid filled swelling, most commonly found in the lower lip. ${ }^{1}$ High frequency laser is required to treat the mucocele, which helps in precision cutting and reduces the risk of necrosis. ${ }^{2,3}$ Re-epithelialization takes about 2-3 weeks. ${ }^{3}$

\section{Oral papillomatosis}

It can be treated with a carbon dioxide laser or an Nd:YAG. ${ }^{4}$

\section{Verrucous carcinoma}

Verrucous carcinoma is a cancerous lesion with a poor prognosis. It is treated by Nd:YAG contact laser and carbon dioxide using excisional technique. Herein there is a wide lesion excision which includes the base of the lesion with wide margins. ${ }^{5}$

\section{Aphthous ulcers}

Aphthous ulcers are painful and often recurrent. Laser treatment of aphthous ulcers is an alternative to temporary palliative pharmacologic therapy. The laser provides relief of pain and inflammation, with normal wound healing of this uncomfortable and potentially recurrent oral lesion. Lasers when used in defocused mode removes exposed nerve endings. The lesion can be rendered insensitive at low wattage within 4 minutes or less. Healing time is reduced markedly. ${ }^{6,7}$ These lesions are usually found on the lips, buccal mucosa, tongue, soft palate and floor of the mouth. Clinically aphthous ulcer appears as a yellowish white pseudo membrane surrounded by erythematous halo. Recently Low Level Laser Therapy (LLLT) has been used. It helps in immediate pain relief and accelerates wound healing. According to De Souza et al, $75 \%$ of the patients reported that there is a significant pain relief in the same session after laser treatment and the lesion is totally regressed in 4 days. When steroids are used, it takes 5-7 days for regression, Bladowski et al also found that diode laser used at low levels reduces the wound healing period to half compared to pharmaceutical method. ${ }^{8,9}$ 
Aphthous ulcers should be treated within the first 48 hours for best results. A 400 micron tip is used for small lesions. The laser defocused mode 5-6mm away from the lesion and advanced towards the periphery $2 \mathrm{~mm}$ away. Continual movement from the periphery to the center is done.15-20 seconds period is given between the laser allowing the tissue to cool. The area, a wet gloved finger to determine if there is reduced pain felt. 2nd and 3rd pass need to be done to completely reduce the pain. After every application of laser, the area should be palpated to check for reduced pain. ${ }^{10,11}$

\section{Herpes labialis and herpetic gingivostomatitis}

It is caused by Herpes virus. It can be seen on the labial mucosa as well as on the gingiva. The use of soft tissue lasers helps in fading off the effects of herpes virus infections, which is caused by the infusion of the laser. The laser interrupts the action of virus, arresting the progress of the lesion. Herpes labialis has been canned successfully with Nd:YAG lasers. ${ }^{12,13}$

\section{Leukoplakia}

Leukoplakia is the most common potentially malignant lesion of the oral mucosa. Various treatment modalities of this lesion include scalpel excision, electro cautery, cryosurgery, laser surgery and medications. Small lesions can be treated by carbon dioxide laser with a margin of $3 \mathrm{~mm} .{ }^{5}$ Fausto Chiesa et al (1986) treated 92 leukoplakias by $\mathrm{CO} 2$ laser surgery. In another study done by Felix WK Chu et al (1988) wherein he used CO2 laser to treat 29 leukoplakia patients with a follow up, depicted that laser over conventional modes of treatment yielded better results in relation to the precision of tissue removal, damage to adjacent tissue minimized, immediate hemostatic effect, excellent wound healing and effective destruction of abnormal mucosal tissue minimizing recurrences. ${ }^{14}$ Gooris et al. conducted a retrospective study to evaluate the treatment results of $\mathrm{CO} 2$ laser evaporation for 27 cases of leukoplakia of the lip and concluded that selective removal of affected epithelium with minimal damage to surrounding structures is possible using $\mathrm{CO} 2$ laser evaporation. Further they were able to achieve excellent wound healing and good functional result. Treatment can be performed under local anesthesia on an outpatient basis and the recurrence rate is low compared with the recurrence rate after surgical excision. ${ }^{14}$

\section{Oral lichen planus}

It is a common mucocutaneous disease, first defined by Wilson in the year 1869. They are bilateral white striations, papules or plaques on the buccal mucosa, tongue and gingivae. Vander Hem et al published data in the year 2008, wherein he treated 21 oral lichen planus patients with CO2 laser evaporation in the period of 19732003. A follow up period of 1-18 years (mean 8 years) showed that $85 \%$ patients were found to be free of pain while $15 \%$ experienced painful recurrence after treatment. Thus, in conclusion the patients whose condition is unresponsive to topical corticosteroids, $\mathrm{CO} 2$ laser evaporation can cause long-term remission of symptoms and may even be the treatment of first choice in patients suffering from painful oral lichen planus. ${ }^{15}$

\section{Oral submucous fibrosis}

Jawahar R et al in their study had used diode laser to treat trismus in oral submucous fibrosis patients and concluded that Diode laser is a less expensive and alternative method in group III and group IVA cases. Further there was reduced morbidity and was apt for the Asian population. Other advantages like reduced hospital stay and follow up were the reasons in comparison to other surgical methods. ${ }^{16}$ Nayak DR et al used KTP-532 laser to treat 9 oral submucous fibrosis patients and was successful in releasing fibers with minimal morbidity and satisfactory results. ${ }^{16}$ In another study done by Mohan Kameshwaran et al, wherein he treated 15 patients by lysis of the fibrotic bands with a soft tissue laser and adjunctive treatment achieved excellent results over a 12 month follow up. ${ }^{17}$

\section{Erythroplakia}

Erythroplakia is a red lesion which can be managed by surgical excision as well as by $\mathrm{CO} 2$ laser. The excision of the lesion with a wide margin is important rather than in depth, which is due to superficial nature of dysplastic and in situ lesions. ${ }^{18}$

\section{Actinic cheilitis}

$\mathrm{CO} 2$ laser vaporization was found to be an effective office procedure for treatment of actinic cheiltis by Robert J Stanley and Randall K. Roenik in the year 1988. It yielded excellent cosmetic and functional results especially when compared to standard vermillonectomy. Other advantages are minimal morbidity as well as the cost. ${ }^{1}$

\section{Salivary gland pathologies}

Carbon dioxide, diode, and Nd: YAG are the various types of lasers that have been employed to treat sialolithiasis. Sialolithiasis is the disease of the salivary glands, most commonly affecting the submandibular gland among the major salivary glands seen in the oral cavity. ${ }^{19}$ This has been attributed to the anatomical position and age of the patient, with other contributing factors.

\section{Radiation mucositis}

Radiation mucositis remains a common complication of high-dose chemo-radiotherapy regimens, with potentially serious complications due to the immunosuppression. Soft tissue laser therapy has been found to be effective in reducing the oral mucositis lesions and the time of wound healing. ${ }^{20}$

\section{Wound healing}

Low level laser therapy has complex effects on wound healing. The irradiation effect not only depends on the total dose of irradiation but also on the irradiation time and the irradiation mode used at the site. Wound healing is a complex process with local and systemic responses, besides it encompasses quite a lot of types of cells, enzymes, growth factors and other substances. In studies of fibroblast responses to lasers, increased cell division and increased collagen production have been reported..$^{21,22}$

\section{Analgesic effect of the laser}

Analgesic effect of LLLT on nerves supplying the oral cavity have shown that LLLT drops the firing frequency of the nociceptors, with a threshold effect seen in terms of the irradiance required to exert maxim suppression..$^{23}$

\section{Nerve repair and regeneration}

Low level laser therapy has been seen to reduce the production of inflammatory mediators of the arachadonic acid family from injured nerves, and to promote neuronal maturation and regeneration following injury. ${ }^{24,25}$ The LLLT protocols used, typically involve daily irradiation for prolonged periods, for example, 10 days at $4.5 \mathrm{~J}$ per day. ${ }^{24}$ The direct application of this technique to dentistry has yielded positive results in promoting the regeneration of inferior dental nerve (IDN) tissue, damaged during surgical procedures. 


\section{Aesthetic gingival re-contouring and crown lengthening}

Clinicians prefer to use diode laser for optimization of gingival aesthetics as part of the comprehensive orthodontic treatment, ${ }^{26,27}$ in comparison to the conventional gingivectomy which is associated with pain, discomfort, and bleeding.

\section{Oral surgery}

Low level laser therapy at the wavelengths from $632 \mathrm{~nm}$ to 904 $\mathrm{nm}$ have been used to provide analgesic effects following oral surgery, which can be useful during major surgical procedures. ${ }^{28}$

\section{Orthodontics}

Local $\mathrm{CO}_{2}$ laser irradiation has been found to reduce the pain associated with orthodontic force application, without interfering with tooth movement.

\section{Conclusion}

Lasers play an integral part in treating oral mucosal lesions. It is a known fact that laser gives optimum results with greater patient comfort, better healing, no pain or bleeding. However, the initial cost of the laser equipment is an initial hindrance to the new budding dentists, but once purchased and accustomed to its use it yields the best results. Its use is not only limited to oral mucosal lesions alone but also stepping into the field of endodontics and periodontics. Lasers have already established itself in the field of surgery.

\section{Acknowledgments}

None.

\section{Funding}

Nil.

\section{Conflicts of interest}

Authors declare that there is no conflict of interest.

\section{References}

1. Neville BW, Damm DD, Allen CM, et al. J. Oral and Maxillofacial Pathology: third edition. 2012;10:390-454.

2. Catone GA, Alling CC. Laser Applications in Oral and maxillofacial surgery. J Oral Surg. 1969;17:36-40.

3. K S Manjunath, Amal Raj, Jimmy S K R Talukdar, et al. Lasers in the Management of Oral Pre-Malignant Lesions. International Journal of Scientific Study. 2015;3(5):183-186.

4. Luis Silva Monteiro, Ana Azevedo, Susana Cadilhe, et al. Laser treatment of oral vascular malformations. 2014;9:89-90.

5. Reshma j Abrahametal, et al. Laser management of intraoral soft tissue lesions-A review of literature. IOSRJDMS. 2014;13:59-64.

6. Dae-Hyun Lee. Application of Laser in Periodontics. 2007;2:7.

7. Lawrence A. Lasers in Pediatric dentistry. Dent Clin North Am. 2004;48(4):889-922.

8. De Souza To, Martins MA, Bussadori SK, et al. Clinical evaluation of low level laser treatment for recurring aphthous stomatitis. Phtomed laser Surg. 2010;28:85-87.
9. Bladowski M, Konarska-Choroszucha H, Choroszucha $\mathrm{T}$, et al. Comparison of treatment results of recurrent aphthous stomatitis (RAS) with low-and high-power laser irradiation vs. pharmaceutical method (5year study). J Oral Laser Applic. 2004;4:191-209.

10. Walsh LJ. The current status of low level laser therapy in dentistry. Part 1 Soft tissue applications. Australian Dent. J. 1997;42(4):247-254.

11. Walsh LJ. The current status of low level laser therapy in dentistry. Part 2 Hard tissue applications. Australian Dent J. 1997;42(5):302-306.

12. Grace Sun, Jan Tuner. Low-Level Laser therapy in dentistry. Dent Clin North Am. 2004;48(4):1061-1076.

13. Jan Tunér, Grängesberg. Low level lasers in dentistry. The Hayden Institute. 2004;6:8-9.

14. F Wong, J Epstein, A Millner. Treatment of Oral Leukoplakia with Topical Bleomycin. A Pilot Study. Oral Cancer. 1989;64(2):361-365.

15. Farzane Aghahosseini, Fateme Arbabi-Kalati, Leila Ataie Fashtami, et al. Methylene Blue-Mediated Photodynamic Therapy: A Possible Alternative Treatment for Oral Lichen Planus. Lasers Surg Med. 2006;38(1):33-38.

16. DR Lai, HR Chen, LM Lin, et al. Clinical evaluation of different treatment methods for oral submucous fibrosis. A 10-year experience with 150 cases. J Oral Pathol Med. 1995;24(9):402-406.

17. LJ Walsh. The current status of laser applications in dentistry. Australian Dental Journal. 2003;48(3):146-155.

18. George Romanos, Georg-Hubertus. Diode Laser (980nm) in Oral \& Maxillofacial Surgical Procedures: Clinical Observation based on Clinical application. Journal of clinical laser medicine \& surgery. 1999;17(5):193-197.

19. Susmit Sneha, Amit Mhapushar, Santosh Jadhav, et al. Laser in Oral Mucosal Lesions - An innovative tool. Journal of Oral Medicine, Oral Surgery, Oral Pathology and Oral Radiology. 2017;3(2):103-106.

20. Mezawa S, Iwata K, Naito K, et al. The possible analgesic effect of softlaser irradiation on heat nociceptors in the cat tongue. Arch Oral Biol. 1988;33:693-694.

21. Mester AF, Snow JB, Shaman P. Photochemical effects of laser irradiation on neuritic outgrowth of olfactory neuroepithelial explants. Otolaryngol Head Neck Surg. 1991;105:449-456.

22. Solomon A, Lavie V, Ben-Bassat $\mathrm{S}$, et al. New surgical approach to overcome the inability of injured mammalian axons to grow within their environment. J Neural Transplant Plast. 1991;2:243-248.

23. Sarver DM, Yanosky M. Principles of cosmetic dentistry in orthodontics: Part 2. Soft tissue laser technology and cosmetic gingival contouring. Am J Orthod Dentofac Orthop. 2005;127:85-90.

24. Sarver DM, Yanosky M. Principles of cosmetic dentistry in orthodontics: Part 3. Laser treatments for tooth eruption and soft tissue problems. Am J Orthod Dentofac Orthop. 2005;127:262-264.

25. Armida MM. Laser therapy and its applications in dentistry. Pract Odontol. 1989;10:9-16.

26. Peres F, Felino A, Carvalho JF. Analgesic effect of 904-nm laser radiation (IR) in oral surgery. Rev Port Estomatol Cir Maxilofac. 1985;26:205-217.

27. Harazaki M, Isshiki Y. Soft laser irradiation effects on pain reduction in orthodontic treatment. Bull Tokyo Dent Coll. 1997;38:291-295.

28. Turhani D, Scheriau M, Kapral D, et al. Pain relief by single low-level laser irradiation in orthodontic patients undergoing fixed appliance therapy. Am J Orthod Dentofacial Orthop. 2006;130:371-377. 